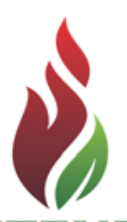

SUSTENERE

Publishing Corporation

\section{POSSIBILIDADES DE EFETIVAÇÃO DE PRÁTICAS DE GOVERNANÇA EM FUNDAÇÕES PRIVADAS}

\section{RESUMO}

O aumento crescente da quantidade e diversidade de organizações sem fins lucrativos, além do expressivo volume de recursos financeiros governamentais e privados carreados para o terceiro setor, tem demandado um maior nível de profissionalização dessas instituições, oportunizando a adoção dos conceitos e das práticas de governança corporativa inicialmente desenvolvida no contexto das empresas privadas com fins lucrativos. Ao utilizar estudo de caso abordando uma fundação privada brasileira, esta pesquisa procurou investigar as possibilidades de efetivação dos princípios e mecanismos de governança corporativa no contexto das fundações privadas, através do exame dos instrumentos e práticas de governança e gestão aplicáveis à realidade organizacional da instituição pesquisada. A análise dos dados coletados a partir da sondagem efetuada permitiu identificar possibilidades de utilização e aprimoramento de importantes instrumentos de governança e gestão na fundação pesquisada, a exemplo da atuação mais efetiva dos conselhos (curador, executivo e fiscal), provimento de equipe técnica de apoio à gestão, uso de metodologia de projetos sociais, atividades de captação de recursos e a existência de um sistema de controles internos.

PALAVRAS-CHAVES: Governança Corporativa; Governança Sem Fins Lucrativos; Organizações Sem Fins Lucrativos; Entidades do Terceiro Setor; Fundações Privadas.

\section{POSSIBILITIES OF GOVERNANCE PRACTICES EFFECTIVE IN PRIVATE FOUNDATIONS}

\section{ABSTRACT}

The increasing amount and diversity of nonprofit organizations, in addition to the significant volume of government and private funds carried to the third sector, has demanded a higher level of professionalism from these institutions, providing opportunities for the adoption of the concepts and practices of corporate governance initially developed in the context of private for-profit companies. Using case study addressing a Brazilian private foundation, this research sought to investigate the possibilities of bringing the principles and mechanisms of corporate governance in the context of private foundations, by examining the tools and practices of governance and management applicable to the organizational reality of the research institution. The analysis of data collected from the survey made it possible to identify possibilities for use and improvement of important instruments of governance and management in the foundation researched, such as the more effective participation of advice (curator, executive and fiscal), provision of technical support staff management, use of methodology of social projects, fundraising activities and the existence of a system of internal controls.

KEYWORDS: Corporate Governance; Nonprofit Governance; Nonprofit Organizations; Third Sector entities; Private Foundations.
Revista Brasileira de

Administração Científica,

Aquidabã, v.5, n.3, Jul, Ago, Set,

Out, Nov, Dez 2014.

ISSN 2179-684X

SECTION: Articles

TOPIC: Terceiro Setor e

Cooperativismo

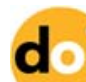

DOI: 10.6008/SPC2179-684X.2014.003.0018

Fernando de Oliveira Canito Filho

Universidade de Fortaleza, Brasil http://lattes.cnpq.br/2695224556269162 fcanito@hotmail.com

Mônica Mota Tassigny

Universidade de Fortaleza, Brasil http://lattes.cnpq.br/4109325305631925 monica.tass@gmail.com

Fabiana Pinto de Almeida Bizarria Universidade de Fortaleza, Brasi http://lattes.cnpq.br/0008637422329772 bianapsq@hotmail.com

Received: 23/02/2014

Approved: $15 / 11 / 2014$ Reviewed anonymously in the process of blind peer.

Referencing this:

CANITO FILHO, F. O.; TASSIGNY, M. M.; BIZARRIA, F. P. A. Possibilidades de efetivação de práticas de governança em fundações privadas. Revista Brasileira de Administração Científica, Aquidabã, v.5, n.3, p.305326, 2014. DOI: http://dx.doi.org/10.6008/SPC2179$684 X .2014 .003 .0018$ 


\section{INTRODUÇÃO}

Oportunizando o desenvolvimento e a consolidação dos princípios e práticas de governança corporativa utilizada para alavancar e impactar positivamente os resultados nas empresas do primeiro (estado) e segundo (mercado) setor, as organizações sem fins lucrativos, também denominadas de terceiro setor (sociedade civil organizada), passam a incorporar esses instrumentos para aprimoramento de sua governança e consequente melhor cumprimento de seu papel institucional. Este é o caso das fundações e associações privadas sem fins lucrativos (FASFIL), que, cada vez mais, devem ter em seus planejamentos estratégicos e na relação com os diversos atores envolvidos no processo - mantenedores, poder público, conselhos, integrantes, fornecedores e, principalmente, a comunidade beneficiada - uma postura lastreada pelos conceitos e instrumentos da boa governança corporativa.

Considerando o grande potencial que o segmento privado das organizações sem fins lucrativos possui para o desenvolvimento socioeconômico e ambiental do país, a presente pesquisa busca contribuir com o aprofundamento dos estudos dos princípios e práticas de governança corporativa aplicável às fundações privadas, cujo tema ainda apresenta uma relativa escassez de trabalhos científicos disponíveis (CORNFORTH, 2003; SANCHES, 2005; RODRIGUES \& MALO, 2006; MINDLIN, 2009; OTHMAN et al., 2012).

Para avaliação das possibilidades de efetividade das práticas de governança corporativa no âmbito das fundações empresariais, este estudo utiliza como parâmetros os princípios e instrumentos referenciados pelos chamados guias ou códigos de melhores práticas de governança aplicáveis às organizações sem fins lucrativos, adotados tanto no Brasil como em outros países.

Nesse sentido, a pesquisa empírica do presente trabalho contempla estudo de caso de uma fundação privada sediada em Fortaleza-Ceará, na região Nordeste do Brasil, com finalidade de atuação voltada para as áreas educacional, cultural, social e beneficente, instituída por uma associação religiosa e atualmente mantenedora de instituição de ensino nos segmentos completos de Educação Infantil, Ensino Fundamental I, Ensino Fundamental II e Ensino Médio/Pré-Vestibular.

Os instrumentos incorporados às boas práticas de governança corporativa, aplicáveis às fundações privadas, convertem princípios em recomendações objetivas que contribuem para um maior alinhamento de interesses entre instituidor-mantenedora e a gestão dessa organização, em conformidade com a causa ou finalidade formalmente estabelecida, preservando a sua reputação e otimizando seu valor social, além de facilitar o acesso a recursos e contribuir para sua longevidade.

No caso do Brasil, de acordo com os dados do estudo do Instituto Brasileiro de Geografia e Estatística - IBGE sobre as Fundações Privadas e Associações sem Fins Lucrativos no Brasil FASFIL (IBGE, 2010), em 2010, as 290,7 mil FASFIL representavam 5,2\% do total de entidades 
públicas e privadas existentes em todo o País. Elas empregavam 4,9\% dos trabalhadores brasileiros, o que representa um contingente de 2,1 milhões de pessoas que ganhavam, em média, R\$ 1667,05 mensais. Este valor equivalia a 3,3 salários mínimos daquele ano, semelhante à média das remunerações de todas as organizações cadastradas no Cadastro Central de Empresas - CEMPRE, do IBGE (3,2 salários mínimos).

Por outro lado, não obstante o interesse crescente das pessoas em atuarem como profissionais de entidades do terceiro setor, Renz (2007) identifica que os candidatos ou mesmo integrantes dos órgãos de administração dessas instituições possuem apenas noções vagas sobre os princípios e práticas de governança, carecendo de um melhor conhecimento quanto à relevância e natureza dos papéis e responsabilidades atribuídas aos colegiados que integram a governança das organizações sem fins lucrativos.

Dessa forma, este trabalho aproveita a premente necessidade de aprimoramento dos conceitos, princípios, instrumentos e práticas de governança corporativa aplicável a organizações sem fins lucrativos, incluindo as fundações privadas, auxiliando na mudança do atual quadro de investigações científicas sobre o tema. De acordo com Mindlin (2009) e Sanches (2005), se apresenta com um número reduzido de estudos, tanto teóricos quanto empíricos, que se dedicam especificamente ao estudo da governança dessas organizações.

Para tanto, o presente estudo se orienta pelo exame das possibilidades de efetivação dos mecanismos de governança corporativa aplicáveis a organizações sem fins lucrativos, no âmbito específico de uma fundação privada voltada para o segmento educacional, no contexto do nordeste brasileiro, contribuindo para o desenvolvimento de conhecimento sobre a governança dessas organizações, que possa ser útil tanto a pesquisadores e estudiosos da administração quanto a gestores engajados nessa atividade.

Após esta introdução, o trabalho se desenvolve apresentando o referencial teórico utilizado, através de dois capítulos abordando: a conceituação de governança corporativa, incluindo a governança aplicável ao terceiro setor e suas melhores práticas consolidadas, tanto em nível nacional quanto internacional. No capítulo a seguir, são descritas as características da pesquisa e as etapas percorridas no marco metodológico da investigação. O capítulo subsequente apresenta a análise dos resultados empíricos coletados, seguido pelas considerações finais.

\section{REVISÃO TEÓRICA}

\section{Governança sem Fins Lucrativos}

Ao processo, estrutura e instrumentos utilizados para minimizar os problemas de agência, de forma a controlar as ações dos gestores e alinhar seus interesses aos do acionista, dá-se o nome de 'governança corporativa', cujos estudos pioneiros iniciados Jensen e Meckling (1976), têm se desenvolvido desde então, viabilizando sua aplicação, principalmente, em companhias 
interessadas em ampliar sua capacidade de financiamento a partir do mercado de capitais e no aprimoramento do processo decisório em nível da alta gestão (SILVEIRA, 2010).

De acordo com Hilb (2009), apenas recentemente a chamada 'Governança sem fins lucrativos' tornou-se o termo padrão das funções de direção e controle de organizações que atuam em causas percebidas como mais nobres, não obstante deva-se reconhecer que, em alguns países, os padrões de governança corporativa para organizações sem fins lucrativos já se encontram bastante desenvolvidos, tornando essas organizações mais transparentes e confiáveis em relação ao seu público.

Embora tenham configuração distinta das empresas tradicionais que normalmente são controladas por proprietários ou acionistas, as organizações sem fins lucrativos (OSFL), incluindo as fundações privadas, possuem finalidades específicas que, à medida que crescem e necessitam delegar responsabilidades a mais pessoas para realização de seus respectivos objetivos, também passam a enfrentar conflitos de interesse entre gestores de diferentes níveis ou entre financiadores e gestores (HILB, 2009).

Rodrigues e Malo (2006) assinalam que as ideias inicialmente propostas pela teoria da agência como base para o surgimento do conceito de governança corporativa foram originadas nas sociedades com fins lucrativos, mas também passaram a influenciar bastante o tratamento da governança em organizações sem fins lucrativos. Embora não exista, neste caso, a figura do acionista, ressaltam os autores, permanece nas entidades do terceiro setor a necessidade de garantir que gestores estejam agindo de acordo com a missão da organização, e não em função de seus próprios interesses.

Para Rassart e Miller (2013), as organizações sem fins lucrativos devem não somente ser bem governadas como também precisam ser percebidas pela sociedade que de fato possuem uma boa governança, especialmente diante dos inúmeros desafios envolvendo: a necessidade crescente de captação de recursos; um aumento cada vez maior da demanda por serviços sociais; a gestão de organizações maiores e mais complexas; a exigência por disponibilização de informações através de mídias sociais e a dificuldade de recrutamento de pessoas qualificadas e disponíveis para composição do Conselho.

Ao analisar a governança corporativa das organizações sem fins lucrativos (OSFL) no contexto americano, Glaeser (2002) faz uma distinção em relação às práticas das companhias que visam ao lucro, identificando, de um lado, os privilégios tributários, o impedimento na distribuição de lucros e a inexistência de proprietários como os principais fatores que explicam o elevado grau de autonomia da direção das OSFL, a cargo do Conselho e da Diretoria Executiva, e, de outro, a competição por clientes e doações como motivações mais importantes do que os instrumentos de controles ou governança na definição da atuação dessas instituições.

Yetman e Yetman (2012) destacam a importância dos relatórios financeiros para o funcionamento das organizações sem fins lucrativos, sugerindo certa semelhança em relação às firmas com finalidade lucrativas no que diz respeito aos efeitos positivos que os mecanismos de 
supervisão e monitoramento presentes na estrutura de governança acarretam no sentido de assegurar a qualidade desses relatórios e contribuir com a mitigação dos eventuais riscos de manipulação de informações.

Ainda em relação à qualidade das informações divulgadas no âmbito das organizações sem fins lucrativos, Souza et al. (2012) salientam que contadores e não contadores atribuem um alto grau de credibilidade à auditoria externa para melhorar a confiabilidade e transparência nas demonstrações contábeis das entidades do terceiro setor, observando que não há diferença significativa entre as percepções dos dois grupos pesquisados.

Para Mähönen (2009), a falta de incentivos e a ausência de controle pelo mercado faz com que a governança das fundações incorra em risco moral (ou moral hazard) e de reputação bem maiores que as empresas que visam ao lucro, exigindo um sistema de supervisão que contemple mecanismos efetivos de incentivos e monitoramento em relação a decisões do Conselho e às ações executadas pelo nível de gestão dessas organizações.

Bradshaw e Hayday (2007), ao revisarem a literatura normativa e acadêmica abordando a governança de organizações sem fins lucrativos, concluíram que não existe um consenso sobre a forma ideal de governança dessas instituições, embora possam ser identificados, segundo esses autores, pelo menos quatro modelos básicos de governança abrangendo as dimensões conservadora/inovadora e unitária/plural: político, empreendedor, representativo e celular.

Por outro lado, Lew e Wójcik (2010), através da análise dos dados das vinte maiores fundações privadas existentes nos Estados Unidos, Reino Unido, Alemanha e Japão, identificaram que essas organizações pesquisadas possuem algumas características semelhantes (tempo de existência, localização, áreas de atuação e ausência de monitoramento de desempenho) e outras bem distintas (formas de captação de recursos e gerenciamento de capital), sendo possível perceber nessas entidades a existência de uma cultura própria de governança filantrópica, embora recebendo alguma influência das suas respectivas culturas nacionais no que tange ao ambiente de negócios e suas práticas de governança.

O modelo político enfatiza a liderança através dos papéis exercidos pelo Conselho (visão, missão, valores, estratégicas e monitoramento do desempenho do nível de gestão) e Diretoria Executiva (nível de gestão que visa o cumprimento da missão institucional). O modelo representativo possibilita uma maior participação das partes interessadas no Conselho, ensejando controle e decisões compartilhadas. Com foco na eficiência e efetividade, o modelo empreendedor prioriza o desempenho da organização, a exemplo das empresas que visam ao lucro. Caracterizado pela existência de uma rede de unidades operacionais autônomas, o modelo celular se distingue pela geração e compartilhamento de know-how, objetivando a um contexto de contínua inovação. De acordo com Crandlemire (2012), é responsabilidade do Conselho (curador ou deliberativo) estabelecer a direção da organização sem fins lucrativos, em consonância com sua finalidade. Webb et al. (2011) ressaltam a importância do Conselho (curador ou deliberativo) para a administração das entidades sem fins lucrativos, até mais do que o papel representado nas 
empresas com finalidade de lucro, se constituindo num recurso estratégico que possibilita às entidades do Terceiro Setor a criação de vantagem relativa através da gestão efetiva dos seus recursos organizacionais. Com base em pesquisa envolvendo cerca de 112 organizações sem fins lucrativo na Flórida (EUA), Hodge e Picoolo (2011) observaram que aquelas entidades que estavam experimentando êxito de forma sustentada possuíam um Conselho (curador ou de liberativo) efetivo em termos de participação no planejamento estratégico e acompanhamento da aplicação dos recursos nas respectivas instituições.

Para a Rede GIFE - Grupo de Institutos, Fundações e Empresas (2009), uma das principais referências no Brasil sobre o investimento social privado, o crescimento do número de fundações e associações privadas brasileiras que realizam investimentos sociais foi acompanhado de uma crescente preocupação das partes interessadas da sociedade em relação a controles, transparência, gestão e prestação de contas dessas organizações, das quais acionistas, órgãos regulatórios, governos, organizações da sociedade civil, consumidores e mídia em geral demandam, cada vez mais, uma melhor governança.

Fontes Filho (2009), ao fundamentar a aplicabilidade dos conceitos e princípios de governança corporativa para utilização em cooperativas de crédito no Brasil, afirma que a utilidade das práticas de governança corporativa não se aplica apenas para empresas privadas, mas também para empresas sem fins mercantilistas ou de lucro, como organizações não governamentais, associações e cooperativas, destacando que, embora a denominação governança corporativa seja orientada para o universo das corporações, sua proposta central de disciplinar os papéis e as responsabilidades entre proprietários e investidores ante a administração da empresa encontra aplicação para um amplo conjunto de organizações.

Cabe ressaltar, contudo, que mesmo entre as empresas que visam ao lucro, onde se verifica uma forte exigência dos investidores no sentido que essas companhias adotem boas práticas de governança, há o reconhecimento de que a adoção de uma estrutura adequada de governança tem ocasionado um crescente aumento dos custos para essas organizações, em muitos casos sem ainda um claro conhecimento dessa magnitude, considerando que estes se encontram distribuídos em diversos centros de custos (SEGRETI et al., 2005).

Dessa forma, abre-se a oportunidade para o desenvolvimento de novos modelos de governança e gestão das entidades do terceiro setor, a exemplo das chamadas 'organizações sem fins lucrativos conectados' que, mediante a intensa utilização de redes sociais baseadas na Internet, constroem e dão apoio a relacionamentos significativos com pessoas que oferecem suporte de uma maneira que vai muito além de doações, ampliando as possibilidades de participação de voluntários em todas as partes do mundo, em torno de causas objetivando o bem comum (KANTER et al., 2011).

Cabe acrescentar, ainda, a observação de Rodrigues (2008) quanto à complexidade e fragmentação presente na dinâmica de funcionamento das entidades do terceiro setor, incluindo as fundações privadas, cuja estrutura organizacional, incluindo os componentes de governança e 
gestão, pode ser percebida como algo que mais do que uma simples moldura ou arranjo de relações, ao possuírem parodoxos e conflitos que demandam abordagens teóricas mais ricas em interpretação. Nesse sentido, Pinto (2003) sugere que as fundações poderiam ser provedoras de modelos que viabilizassem a flexibilização organizacional, ou seja, que adotassem parâmetros de eficiência presente na racionalidade instrumental da lógica de mercado, mas que também buscassem adotar uma praxis administrativa com ênfase na racionalidade substantiva, pautada pela promoção do envolvimento consciente dos funcionários no processo de trabalho, num contexto de gestão de natureza mais participativa.

\section{Melhores Práticas de Governança para Fundações}

Iniciando com a divulgação do Relatório Cadbury, em 1992, a proposição de códigos de boas práticas de governança corporativa acelerou-se a partir de 1999, com a publicação do documento Principles of Corporate Governance, elaborado pela Organization for Economic Cooperation and Devolepment, ou, com a sigla em português OCDE (Organização para a Cooperação e o Desenvolvimento Econômico), organização multilateral que congrega os 30 países industrializados mais desenvolvidos do mundo (ROSSETTI, 2011). Através de seu website, o European Corporate Governance Institute disponibiliza o conteúdo dos códigos de governança editados por vários países, sendo que alguns deles já se encontram em sua segunda ou terceira versão, revelando o amplo interesse pelo processo de governança e sua permanente adaptação às mudanças no ambiente interno e externo das corporações existentes nessas nações.

No Brasil, a divulgação de códigos de boas práticas de governança corporativa para as empresas com fins lucrativos, ou de mercado, tem sido liderada pelo Instituto Brasileiro de Governança Corporativa (IBGC), através do 'Código das Melhores Práticas de Governança Corporativa', cuja primeira versão do documento foi publicada em 1999 e, atualmente, encontra-se disponível em sua quarta edição 2010. A preocupação com melhores práticas em governança e gestão também tem sido verificada nas organizações sem fins lucrativos, conforme observa Drucker (2006), ao constatar que as entidades do terceiro setor americano tem se mostrado líderes nas áreas de estratégia e atuação de conselhos de administração, além de inovadoras, quando se trata de motivação e produtividade dos trabalhadores do conhecimento.

Ao utilizar sua abordagem de análise denominada de 'good-to-great', Collins (2005) constatou que os princípios identificados nas empresas lucrativas consideradas "grandiosas" (definindo grandeza, liderança nível 5, primeiro quem-depois o quê, o conceito do porco-espinho e o efeito-volante) se aplicam também às organizações do setor social, 'talvez até melhor do que o esperado', concluindo que a grande questão que diferencia as organizações na forma de serem adequadamente administradas não está se elas atuam nos setores de negócios ou sociais, mas se são 'grandiosas' ou apenas 'boas'. 
Pioneira na divulgação de códigos de melhores práticas para empresas lucrativas, a OCDE, embora reconheça que os seus 'Princípios OCDE sobre o Governo das Sociedades' foram concebidos tendo em mente as sociedades de capital aberto ao público, tanto financeiras como não financeiras, esclarece que na medida em que sejam aplicáveis, 'Os Princípios' poderão ser uma ferramenta útil para melhorar também o governo das sociedades com o capital fechado ao investimento do público, quer sejam empresas privadas ou empresas públicas (OCDE, 2004).

De modo mais específico para as entidades do terceiro setor, o 'Code Steering Group' (CSG), integrado por representantes de várias organizações voluntárias e comunitárias sediadas na Inglaterra, publicou, em outubro de 2010, sua segunda edição (a primeira foi editada em 2005) do documento 'Good Governance - A Code for the Voluntary e Community Sector', contemplando os princípios da chamada 'Boa Governança' que devem nortear a atuação de curadores, membros de Conselhos e gestores dessas instituições no contexto britânico.

O documento 'the Code', como é chamado referido Código, apresenta seis princípios a serem observados por aqueles que exercem funções de liderança ou são membros efetivos de Conselhos de organizações voluntárias e comunitárias: Compreensão clara do respectivo papel institucional; Compromisso com os propósitos da organização; Desenvolvimento de pessoas e da equipe; Controle efetivo da organização; Postura de integridade e ética e Transparência nas informações para os públicos internos e externos (CSG, 2010).

O propósito dos seis princípios apresentados pelo 'the Code', conforme descrição resumida no Apêndice $B$ deste trabalho é auxiliar os membros de Conselhos de organizações voluntárias e comunitárias no exercício efetivo de uma forte liderança, com aprimoramento no processo de tomada de decisões e no aperfeiçoamento de políticas e procedimentos de prestação de contas que contribuam para a consecução dos objetivos dessas instituições junto às comunidades a serem beneficiadas. O princípio 4 estabelece que um Conselho (curador ou deliberativo) deve assegurar que a organização sem fins lucrativos, incluindo as fundações privadas, conheça e revise regularmente os riscos envolvidos, esteja em conformidade com as exigências legais e regulatórias e disponha de controles financeiros adequados. Para Gunderson (2008), essas devem ser as principais preocupações de um efetivo Sistema de Controles Internos que toda entidade do terceiro setor deve implementar e monitorar.

No tocante ao princípio '5. Postura de Integridade Ética', cabe destacar a recomendação adicional do CSG para observância de padrões éticos de comportamento por parte de líderes e conselheiros de organizações voluntárias e comunitárias, a exemplo dos 'Sete Princípios da Vida Pública', de Lord Nolan, a saber: Interesse Público; Integridade; Objetividade; Prestação de Contas; Transparência; Honestidade e Liderança (ENAP, 1997). Além dos padrões éticos ressaltados pelo 'the Code' a serem observados pelos líderes e conselheiros das organizações sem fins lucrativos, relaciona diversos fatores que devem ser considerados para composição do Conselho (curador ou deliberativo), a exemplo da experiência do indivíduo, o conhecimento que possui em relação à missão da organização, uma rede de relacionamentos que seja relevante 
para a atuação da entidade e, o mais importante, que não ocupe cargos de gestão na própria instituição a fim de evitar eventuais conflitos de interesses.

No caso brasileiro, em 2009, a Rede GIFE (Grupo de Institutos, Fundações e Empresas), em parceria com o Instituto Brasileiro de Governança Corporativa (IBGC), publicou o "Guia das Melhores Práticas de Governança para Fundações e Institutos Empresariais", considerado uma referência no contexto nacional no que diz respeito à boa administração dessas organizações sem fins lucrativos em um ambiente autorregulado.

\section{METODOLOGIA}

De acordo com a classificação proposta por Patton (1990), a presente pesquisa é considerada do tipo aplicada, levando em conta que a fonte das questões de pesquisa é centrada no entendimento da natureza de determinados problemas com o propósito de gerar soluções potenciais a partir da utilização de referencial teórico aplicável. De modo ainda mais específico, levando em conta a tipologia de Roesch (1996), este estudo também pode ser considerado como uma pesquisa-diagnóstico, ao propor a identificação de problemas e a apresentação de sugestões visando resolução das situações organizacionais diagnosticadas como passíveis de aprimoramento. Utiliza metodologia exploratória, cujo objetivo é proporcionar uma visão geral aproximativa de um determinado fato (GIL, 1999), bem como oferecer informações adicionais sobre um assunto a ser investigado, facilitando a delimitação do tema de pesquisa, orientando a fixação dos objetivos e a formulação de hipóteses ou mesmo permitindo a descoberta de um novo tipo de enfoque sobre o assunto pesquisado (BEUREN, 2003).

No tocante aos aspectos empíricos da sua dimensão metodológica, este trabalho contempla estudo de caso abordando o funcionamento de uma fundação privada com atuação preponderante no segmento educacional, sediada na cidade de Fortaleza, capital do estado do Ceará, na região nordeste do Brasil. De acordo com Yin (1990), o estudo de caso é uma forma de se fazer pesquisa social empírica ao investigar-se um fenômeno atual dentro de seu contexto de vida real, onde as fronteiras entre o fenômeno e o contexto não são claramente definidas e na situação em que múltiplas fontes de evidência são usadas. Segundo Cooper e Schindler (2008), ao colocarem mais ênfase em uma análise contextual completa de poucos fatos ou condições e suas inter-relações, os estudos de caso têm um papel científico importante e, quando bem planejados, podem representar um desafio importante para uma teoria e simultaneamente serem a fonte de novas hipóteses e constructos.

A seleção do caso a ser estudado levou em conta a lista de critérios sugeridos por Miles e Huberman (1994), a saber: relevância no tocante ao quadro referencial e para as questões de pesquisa; identificação do fenômeno a ser investigado; possibilidade de comparação e generalização com outros casos; descrições e explanações guardam consonância com a vida 
real; viabilidade em relação ao acesso a dados, custo envolvido e tempo para coleta de dados; e atendimento a princípios éticos.

\section{Coleta e Tabulação dos Dados}

A etapa de coleta de dados utilizou os instrumentos de pesquisa bibliográfica e documental, necessária para conhecimento prévio do estágio em que se encontra o assunto a ser investigado, e de entrevista estruturada, onde o entrevistado segue uma sequencia padronizada de perguntas com linguagem sistematizada, preferencialmente fechada, voltadas para a obtenção de respostas concisas em torno dos aspectos abordados (MARCONI \& LAKATOS, 1990). Através de formulário de pesquisa estruturada ou padronizada (GRESSLER, 2003), durante os meses de maio e de junho de 2013, foram entrevistados, presencialmente, os membros titulares dos órgãos estatuários de administração da Fundação pesquisada, incluindo respondentes do Colégio Deliberativo, Conselho Fiscal e Conselho Diretor.

$\mathrm{Na}$ elaboração do formulário de pesquisa utilizado nas entrevistas com os administradores da Fundação pesquisada, foi adotada uma escala do tipo 'Likert', instrumento de resposta psicométrica usada habitualmente em questionários e em pesquisas de opinião, contemplando os seguintes níveis de resposta: Discordo totalmente; Discordo parcialmente; Concordo parcialmente e Concordo totalmente. Dessa forma, o estudo observou os passos recomendados pela literatura que aborda os procedimentos no desenvolvimento de escala (DEVELLIS, 1991; NETEMEYER \& BEADER; SHARMA, 2003) em pesquisas sociais, configura figura 1, a saber: pesquisa bibliográfica sobre o assunto; escolha e validação das questões; seleção das decisões de resposta; definição da escala a ser utilizada; coleta de dados; tratamento dos dados e análise e interpretação dos dados à luz do referencial teórico.

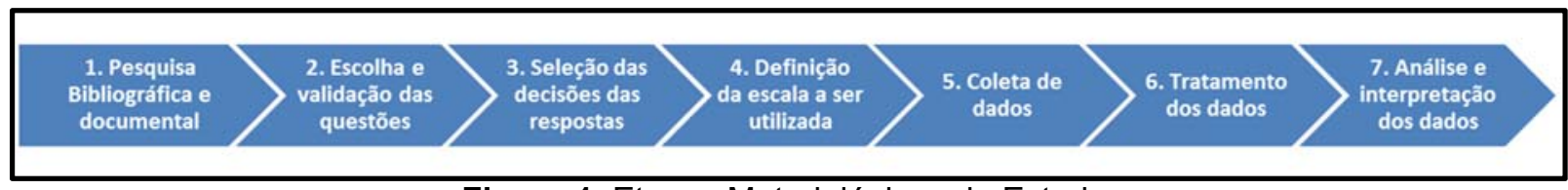

Figura 1: Etapas Metodológicas do Estudo.

Seguindo a sugestão de Silva, Godoi e Bandeira-de-Mello (2006) de que, antes de iniciar o trabalho de campo, é preciso conhecer um pouco da história, da estrutura e do funcionamento da organização, foram também consultados documentos de Livro Ata e Estatuto Social, subsidiando a complementação de informações relacionadas com aos principais macos históricos da organização, além de instrumentos e práticas adotadas pelos níveis de governança e gestão desde a criação da Fundação pesquisada.

Todos os dados coletados foram devidamente tabulados e consolidados em planilhas eletrônicas, possibilitando uma avaliação global, na perspectiva dos entrevistados, do nível de aderência e efetividade dos instrumentos e procedimentos de governança e gestão utilizados pela 
Fundação pesquisada em relação às melhores práticas referenciadas por códigos de governança aplicáveis a organizações sem fins lucrativos, incluindo as fundações privadas.

Referido procedimento observou sugestão de Silverman (2009) no sentido de se incorporar dados quantitativos na pesquisa qualitativa, através da utilização de técnicas de contagem simples, teoricamente derivadas e idealmente baseadas nas próprias categorias dos participantes, oferecendo um meio para examinar todo o corpo de dados utilizados no estudo qualitativo.

\section{RESULTADOS}

Nessa linha, a presente pesquisa se baseia no estudo de caso de uma fundação privada sediada em Fortaleza (CE), no nordeste brasileiro, e criada por dotação especial de bens, por uma instituição religiosa de confissão cristã, com a finalidade de atuação nas áreas educacional, cultural, social e beneficiente. Cabe ressaltar que uma instituição religiosa, pela própria natureza de suas atividades, normalmente promove ações de cunho social que acabam requerendo a criação de uma nova entidade do terceiro setor, especificamente para consecução dessa finalidade, com vistas a oferecer maior transparência e controle do ponto de vista financeiro e contábil (PICCININI, 2013).

Em decorrência do atual direcionamento visando ao desenvolvimento de novos projetos sociais, prioritariamente na área educacional, a instituidora e mantenedora estabeleceu diretriz de fortalecimento da estrutura e dos instrumentos de governança e gestão da Fundação pesquisada, como forma de potencializar e conferir maior eficácia às suas ações de natureza social junto às comunidades onde atua enquanto organização religiosa. Vale ressaltar que o direcionamento definido pela instituidora no sentido de fortalecer os instrumentos de governança e gestão da Fundação pesquisada encontra-se alinhado com as práticas de outras instituições religiosas que também estão comprometidas com uma abordagem de excelência na administração organizacional, adotando padrões, estruturas e procedimentos que ofereçam maior transparência e eficácia no alcance dos objetivos dessas instituições (NCVO, 2007; FAITHWORKS, 2008).

Levando em conta que a adoção de princípios e instrumentos de governança corporativa normalmente acarretam uma maior demora na tomada de decisão e um aumento dos custos decorrentes da necessidade de ampliação da estrutura de gestão da organização (COSTA, 2008), a liderança da instituidora e mantenedora considerou necessária uma avaliação mais aprofundada quanto ao estágio atual bem como quanto às possibilidades de efetivação e benefícios decorrentes do aprimoramento das práticas de governança da Fundação pesquisada.

O interesse da instituidora e mantenedora no aprimoramento dos mecanismos de governança e gestão da Fundação pesquisada, além da facilidade de acesso aos administradores dessas organizações, ambas sediadas em Fortaleza, viabilizaram, de acordo com o planejamento deste trabalho, o esforço dispendido na realização de entrevistas e obtenção de documentação, constantes da etapa de coleta de dados da presente pesquisa. Cabe salientar que a Fundação 
pesquisada já existe há mais de vinte e cinco anos, com atuação no segmento educacional, através duas unidades de ensino, sediadas na cidade Fortaleza (CE), voltadas para a prestação de serviços nos segmentos de Educação Infantil, Ensino Fundamental I, Ensino Fundamental II e Ensino Médio/Pré-Vestibular.

Conforme Figura 2, descrita a seguir, a Fundação pesquisada, para consecução de suas finalidades, conta com os seguintes órgãos administrativos estatutariamente definidos: Colégio Deliberativo, órgão soberano para as principais deliberações da Fundação; Conselho Fiscal, órgão independente e de fiscalização da administração contábil-financeira da Fundação; e do Conselho Diretor, órgão administrativo e executivo da citada instituição.

São atribuições estatutárias do Colégio Deliberativo da Fundação Pesquisada, dentre outras, definir e revisar estratégias e objetivos a serem alcançados, estabelecer diretrizes de atuação do Conselho Diretor, aprovar o plano de atividades e a previsão orçamentária anual, apreciar e aprovar a criação de estruturas administrativas, aprovar plano de cargos e salários, além de examinar e aprovar a prestação de contas anual.

Compete ao Conselho Fiscal fiscalizar os atos do Conselho Diretor à luz dos seus deveres legais e estatutários, analisar e elaborar parecer sobre a prestação de contas, informar ao Colégio Deliberativo eventuais irregularidades da administração no desempenho de suas atribuições, além de examinar e emitir pareceres sobre demonstrações contábeis e demais dados concernentes à prestação de contas perante o Ministério Público.

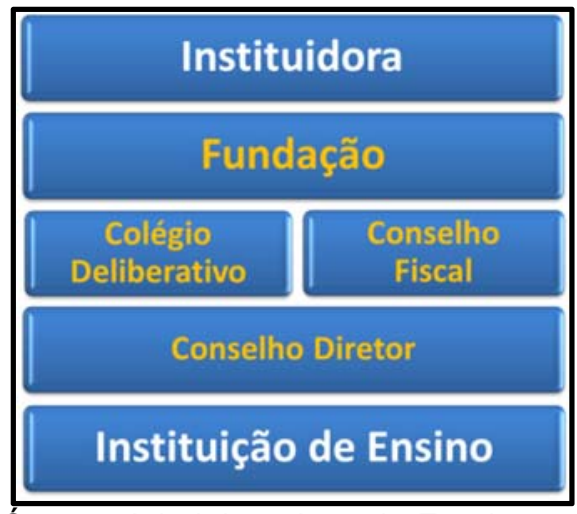

Figura 1: Orgãos Administrativos da Fundação Pesquisada.

O Conselho Diretor é responsável pela gestão das atividades técnicas, administrativas e financeiras da Fundação pesquisada, incluindo a elaboração do planejamento das ações e da proposta orçamentária, bem como da apresentação da prestação de contas a ser submetida à apreciação do Conselho Fiscal, aprovação do Colégio Deliberativo e posterior encaminhamento ao Ministério Público, responsável pelo velamento das fundações. O Conselho Diretor poderá criar órgãos singulares ou coletivos para auxiliá-lo na gestão e no cumprimento das finalidades da citada instituição, observadas as diretrizes e decisões do Colégio Deliberativo.

No âmbito da sua finalidade de promover a educação como ferramenta de desenvolvimento humano, vincula-se à Fundação pesquisada uma instituição de ensino, 
funcionando atualmente com duas unidades sediadas na cidade Fortaleza (CE), voltadas para os segmentos de educação infantil, ensino fundamental (I e II), médio e pré-vestibular. Por possuir sede própria e foro na cidade e comarca de Fortaleza, Capital do Estado do Ceará, na região do Nordeste do Brasil, a Fundação pesquisada, de acordo com o estabelecido no Art. 66 do Código Civil, deve submeter sua prestação anual de contas, além dos eventuais pedidos de alteração estatutária, ao Centro de Apoio Operacional dos Registros Públicos das Fundações e das Entidades de Interesse Social, vinculado ao Ministério Público do Estado do Ceará.

\section{Finalidade}

$\mathrm{Na}$ avaliação dos entrevistados, a Fundação pesquisada carece de uma revisão na sua missão/finalidade estatuariamente definida. Tal aperfeiçoamento permitiria um maior foco de sua atuação bem como a mitigação dos eventuais riscos de desassistência de sua causa e consequentes sanções por parte do Ministério Público, no âmbito de sua responsabilidade pelo velamento das fundações (PAES, 2013).

\section{Conselho (Curador ou Deliberativo)}

No tocante ao Conselho (curador ou deliberativo), os administradores da Fundação pesquisada consideram que as atribuições desse colegiado 'estão definidas, porém não cumpridas', ou seja, se encontram adequadamente formalizadas em Estatuto Social, mas apresentam deficiências no tocante à execução dessas responsabilidades. Nesse sentido, os respondentes destacaram que o Conselho (curador ou deliberativo): não tem definido políticas visando claramente delimitar o exercício do poder decisório dos executivos (obviamente, sem tolher a capacidade de planejamento e execução das atividades de gestão da Fundação) e não tem realizado com regularidade suas reuniões ordinárias, com comunicação prévia de pauta e registro em ata, garantido a efetividade dos trabalhos desse colegiado.

Medidas que contribuam para tornar mais efetiva a atuação do Conselho (curador ou deliberativo) são de fundamental importância para o funcionamento adequado das fundações privadas e, em consequência, a consecução da respectiva finalidade estatutariamente prevista para estas instituições, tendo em vista o papel proeminente desse colegiado na definição das políticas de governança e no estabelecimento do direcionamento estratégico dessas entidades (CRANDLEMIRE, 2012; GRAZIOLLI, 2011; HODGE \& PICCOLO, 2011; PAES, 2011; WEBB et al., 2011).

Os entrevistados também entenderam como necessária a revisão do perfil de competências para composição do Conselho (curador ou deliberativo), contribuindo para o fortalecimento desse colegiado. Nesse sentido, cabe considerar os padrões éticos de comportamento (CSG, 2010; ENAP, 1997), além dos aspectos envolvendo experiência, 
conhecimentos, rede de relacionamentos, motivação e disponibilidade de tempo (IBGC, 2009), exigidos para os líderes e conselheiros das organizações sem fins lucrativos, incluindo as fundações privadas.

\section{Diretoria Executiva (ou Conselho Diretor)}

Embora tenham avaliado como adequadas as atribuições da Diretoria Executiva (ou Conselho Diretor) definidas em Estatuto Social, os respondentes afirmaram que 'não há diretrizes fixadas pelo Conselho (curador ou deliberativo)', ou seja, inexiste um direcionamento estratégico formalizado que oriente a atuação do nível de gestão da fundação pesquisada. Cabe ressaltar que a falta de um balizamento que norteie a atuação dos executivos no cumprimento da finalidade da organização fragiliza o alinhamento de metas e agendas com as prioridades estratégicas, aspecto considerado como um dos pilares da boa governança das entidades do terceiro setor, incluindo as fundações privadas. Houve praticamente um consenso por parte dos administradores da Fundação pesquisada quanto à necessidade premente de provimento de uma equipe técnica para auxílio à Diretoria Executiva (ou Conselho Diretor) nas suas atividades de gestão. Considerando a responsabilidade do nível de gestão na condução de vários processos de suporte ao funcionamento das organizações sem fins lucrativos, incluindo as fundações privadas (WORTH, 2013), é fundamental que essa instância de governança conte com o auxílio de uma estrutura organizacional compatível com o esforço requerido para execução das atividades operacionais que assegurem o efetivo cumprimento das finalidades da instituição, em consonância com as estratégias definidas pelo Conselho (curador ou deliberativo).

Os entrevistados também identificaram que a Fundação pesquisada não possui processos de avaliação de desempenho da própria Diretoria Executiva (a ser avaliada pelo Conselho curador ou deliberativo) e da equipe técnica (nesse caso, a ser avaliada pela Diretoria Executiva), nem tampouco existe política de remuneração e concessão de benefícios para a equipe técnica, em consonância com as diretrizes definidas pelo Conselho (curador ou deliberativo). Segundo Moyers (2006), uma das dez responsabilidades básicas do Diretor Executivo nas organizações sem fins lucrativos, incluídas as fundações privadas, é a de gestão de pessoas, incluindo contratação, treinamento, desenvolvimento e avaliação, da equipe que the dará apoio na execução das atividades operacionais visando cumprir eficazmente a finalidade da instituição.

Os entrevistados afirmaram que 'as ações promovidas pela Fundação não são organizadas na forma de projetos sociais'. Além disso, os respondentes identificaram que a 'Fundação não realiza, planejada e organizadamente, atividades de captação de recursos', com implicações para a sustentabilidade financeira das ações desenvolvidas pela citada instituição, visando cumprimento de sua finalidade. De acordo com Santos et al. (2008), as organizações sem fins lucrativos, incluindo as fundações privadas, necessitam de maior profissionalização de suas atividades de captação de recursos financeiros visando possibilitar seu acesso à concorrida oferta 
de recursos financeiros para fins sociais. Nesse sentido, torna-se indispensável o desenvolvimento de práticas de elaboração e gestão de projetos, incluindo o planejamento (definição de objetivos, metas, público-alvo, custos, prazos, responsabilidades) e acompanhamento sistemático dessas iniciativas através de adequados instrumentos de monitoramento e avaliação.

Ainda como evidência da inadequação da estrutura de gestão da Fundação pesquisada, os respondentes identificaram: a ausência de políticas de comunicação e de relacionamento com as partes interessadas; a inexistência de um Sistema de Controles Internos; e a falta de um processo adequado de divulgação de relatórios financeiros e operacionais. Para Gunderson (2008), toda organização sem fins lucrativos, incluindo as fundações privadas, deve assegurar a existência de um Sistema de Controles Internos que contemple políticas e procedimentos visando proteção dos ativos, elaboração de relatórios financeiros fidedignos para os públicos internos e externos, conformidade com leis e regulamentos e alcance dos objetivos operacionais de modo efetivo e o mais eficiente possível.

Em relação aos relatórios periódicos, Yetman e Yetman (2012) destacam a importância da divulgação desses instrumentos com informações fidedignas, levando em conta a necessidade das várias partes interessadas (doadores, parceiros e órgãos de regulação) em acompanharem o real desempenho das organizações sem fins lucrativos, incluindo as fundações privadas, além de se constituírem em fonte indispensável de informações para subsidiar decisões e alocação de recursos dessas instituições. Os administradores da Fundação pesquisada reconheceram que 'não há um código de conduta' devidamente aprovado pelo Conselho, a ser observado pela Diretoria Executiva (ou Conselho Diretor) e sua equipe técnica de apoio. Considerando a importância dos aspectos éticos para as organizações sem fins lucrativos, incluindo as fundações privadas, é indispensável a elaboração e divulgação de um código de conduta que explicite os comportamentos esperados de conselheiros, gestores, funcionários e voluntários, enunciando com clareza os princípios e valores presentes na cultura da organização e apresentando caminhos para denúncias ou resolução de dilemas de ordem ética (CHÊNE, 2009)

Os entrevistados afirmaram, ainda, que a Fundação pesquisada também não conta com o apoio de Auditoria Externa Independente na avaliação periódica das demonstrações financeiras e do Sistema de Controles Internos, incluindo a geração de relatório circunstanciado específico para o período fiscal analisado, mediante contratação e fixação de plano de trabalho e honorários pelo Conselho (curador ou deliberativo) para a realização de tais serviços. Cabe lembrar que, de acordo com Souza et al. (2012), a auditoria externa, na percepção dos próprios contadores, contribuem com a melhoria da confiabilidade e transparência nas demonstrações contábeis das entidades do terceiro setor, incluindo as fundações privadas. Além disso, normalmente o exame dos registros e práticas contábeis por uma auditoria externa independente se constitui em requisito de ordem legal ou decorrente de exigências demandas por instituições provedoras de recursos financeiros. 


\section{Conselho Fiscal}

Em relação ao Conselho Fiscal da Fundação pesquisada, os respondentes entenderam que, não obstante a adequação das atribuições no Estatuto Social, referido colegiado não tem exercido adequamente essas responsabilidades, demonstrado pela inexistência de agenda de trabalho informando o calendário de reuniões ordinárias e a não divulgação de pareceres e/ou documentos contemplando o registro dos votos e as respectivas justificativas dos conselheiros fiscais.

Segundo Paes (2013), o Conselho Fiscal é o órgão que na estrutura de administração da entidade fundacional tem como competência a fiscalização da gestão econômico-financeira da fundação, incluindo o exame das suas contas, balanços e quaisquer outros documentos requeridos, com emissão de parecer contábil de periodicidade, no mínimo, anual. De acordo com o IBGC (2009), a existência de um Conselho Fiscal efetivo é considerada boa prática para as organizações sem fins lucrativos, incluindo as fundações privadas, tendo em vista a necessidade de que essas instituições assegurem o acompanhamento da execução financeira de recursos (privados ou públicos) captados para aplicação no interesse público.

\section{Adoção de Práticas e Instrumentos de Governança e Gestão}

Houve um consenso entre os administradores da Fundação pesquisada quanto à exequibilidade de implementação, bem como no tocante à efetividade em termos de benefícios esperados para o fortalecimento da administração da citada instituição, considerando o cenário de adoção dos instrumentos e práticas de governança e gestão referenciadas através das perguntas formuladas em cada entrevista realizada.

Diante da constatação de que a efetivação de instrumentos e melhores práticas de governança e gestão acarretam custos adicionais para as empresas que visam lucros bem como para as entidades do terceiro setor, incluindo as fundações privdadas, (SEGRETI et al., 2005), a implementação dos aperfeiçoamentos necessários à estrutura organizacional da Fundação pesquisada ocorrerá, segundo posicionamento dos administradores da citada entidade, de forma gradual e de acordo com a respectiva dinâmica de desenvolvimento institucional.

\section{DISCUSSÃO}

A análise e interpretação dos dados coletados durante as entrevistas com os administradores da Fundação pesquisada, à luz do arcabouço teórico utilizado no presente estudo, revelam a inexistência ou necessidade de aprimoramento de vários instrumentos e mecanismos de governança e gestão, especialmente quando se compara com as melhores 
práticas existentes nos códigos de governança voltados para as organizações sem fins lucrativos, incluindo as fundações privadas.

Cabe ressaltar que a situação organizacional observada na Fundação privada brasileira objeto do estudo de caso pesquisado não é muito diferente do cenário verificado nas organizações sem fins lucrativos, incluindo as fundações privadas, de outros países em desenvolvimento (OTHMAN, 2012). Em ambos os casos, o aperfeiçoamento dos instrumentos e mecanismos de governança e gestão das entidades do terceiro setor exigirá um maior nível de qualificação de seus administradores e equipes técnicas, acompanhado do atendimento das necessidades de recursos financeiros que assegurem o adequado funcionamento dessas instituições.

Além disso, de acordo com as conclusões do estudo desenvolvido por Silva e Aguiar (2011), o próprio monitoramento efetuado pelo Ministério Público, com base na sua função de legal de velamento das fundações, deverá ser um importante fator de indução para que a instituição pesquisada no presente trabalho promova o aperfeiçoamento gradual de seus instrumentos de governança e gestão, a partir do esforço de ampliação de suas atividades visando cumprimento da finalidade estatuariamente definida. Em todo caso, é importante observar que os resultados analisados na presente pesquisa, envolvendo os instrumentos e mecanismos de governança e gestão da Fundação pesquisada, estão mais relacionados com a lógica interna de funcionamento da citada entidade segundo uma ótica da racionalidade instrumental, sem levar em conta outros referenciais de natureza mais substantiva que devem também ser utilizados nas práticas administrativas das organizações sem fins lucrativas, incluindo as fundações privadas (PINTO, 2003).

\section{CONCLUSÕES}

O aumento crescente da quantidade e diversidade de organizações sem fins lucrativos, além do expressivo volume de recursos financeiros governamentais e privados carreados para o terceiro setor, tem demandado um maior nível de profissionalização dessas instituições, oportunizando a adoção dos conceitos e das práticas de governança corporativas inicialmente desenvolvidas no contexto das empresas privadas com fins lucrativos. Não obstante a reconhecida importância das organizações sem fins lucrativos, tanto em nível nacional quanto internacional, apenas recentemente deu-se início ao debate profissional e acadêmico em torno da chamada "governança sem fins lucrativos", com vistas ao aprimoramento da administração dessas entidades e, em consequência, contribuindo para uma maior eficácia e transparência no cumprimento de suas respectivas finalidades.

Ao utilizar estudo de caso abordando uma fundação privada brasileira, o presente trabalho contribui para a mudança do atual quadro de relativa escassez de estudos científicos sobre o tema, investigando as possibilidades de efetivação dos princípios e mecanismos de governança 
corporativa no contexto das fundações privadas, através do exame dos instrumentos de governança e gestão aplicáveis aos principais desalinhamentos identificados na organização pesquisada. Através da análise dos dados coletados e tabulados a partir de entrevistas realizadas com os administradores da Fundação pesquisada, à luz do referencial teórico utilizado, foi possível atingir o objetivo geral definido para o presente trabalho, no sentido de verificar as possibilidades de efetivação dos princípios, instrumentos e práticas de governança aplicáveis em fundações privadas.

Como evidência que reforça a constatação do atingimento do objetivo geral deste trabalho, os administradores da instituidora e da própria Fundação pesquisada utilizaram os resultados do presente estudo de caso como subsídios para nortear o esforço que já está sendo conduzido por equipe multidisciplinar visando execução de plano de ação voltado para a implementação de melhorias em termos de finalidade, estrutura organizacional e práticas de governança e gestão no âmbito das ações sociais realizadas através dessas organizações.

A etapa de análise e interpretação dos dados coletados durante as entrevistas com os administradores revelou que a inexistência de alguns instrumentos e melhores práticas de governança aplicáveis às organizações sem fins lucrativos, incluindo fundações privadas, a exemplo da ausência de políticas claramente definidas pelo Conselho (curador ou deliberativo) visando delimitar o exercício do poder decisório da Diretoria Executiva e a falta de avaliação sistemática do desempenho desses gestores tem acarretado desalinhamentos no âmbito da governança da Fundação pesquisada.

Além disso, foram identificadas oportunidades de aprimoramento em importantes instrumentos de governança utilizados pela organização pesquisada, cujo aperfeiçoamento tornaria mais eficaz o esforço da instituidor-mantenedora na definição e monitoramento da missão, diretrizes e objetivos da Fundação, como é o caso da necessidade de uma maior efetividade dos trabalhos do Conselho (curador ou deliberativo) por meio da realização sistemática de reuniões ordinárias com comunicação prévia de pauta e registro em ata dos temas e deliberações efetuadas por esse colegiado. Foi possível, ainda, constatar que vários instrumentos de gestão aplicáveis ao funcionamento de fundações, a exemplo de equipe técnica de apoio aos executivos, sistema de controles internos, código de conduta, metodologia de projetos sociais e atividades sistemática de captação de recursos, carecem de implementação visando contribuir para uma maior autonomia, conformidade legal e eficácia no cumprimento das finalidades previstas no Estatuto Social da Fundação pesquisada.

Como um ponto complementar aos objetivos específicos respondidos pela pesquisa, conforme acima mencionado, o estudo de caso investigado permitiu confirmar a necessidade de um maior nível de profissionalização por parte da Fundação pesquisada, requerendo maiores investimentos em capacitação e estruturação no nível organizacional da entidade, a fim de conferir efetividade na implementação de instrumentos e práticas de governança e gestão que contribuam com um maior desempenho na consecução da finalidade da citada instituição. 
Analisando sob a perspectiva dos modelos teóricos de governança referenciados neste trabalho, o caso estudado revelou que a boa governança não se configura através da utilização das características de uma única abordagem, mas passa pela complementaridade das propostas existentes: fortalecimento dos instrumentos de monitoramento e controle (teoria da agência); aprimoramento de ferramentas de gestão, visando maior autonomia do nível executivo (teoria da hegemonia gerencial); implantação de processo contínuo de captação de recursos financeiros voltados para a sustentabilidade dos projetos sociais (teoria da dependência de recursos); e adoção de práticas voltadas para o atendimento dos interesses das várias partes interessadas na organização (teoria dos stakeholders).

Como limitação do presente trabalho, cabe destacar a utilização de um único caso a ser estudado, com características bem específicas em termos da instituidora e da própria fundação investigada. Para estudos futuros, no âmbito científico, sugere-se a aplicação de questionários para um número e diversidade maiores de fundações, incluindo finalidades, áreas de atuação, público-alvo e porte distintos, como critérios para seleção das organizações a serem pesquisadas. Adicionalmente, propõe-se o desenvolvimento de novos estudos teóricos e empíricos sobre governança de organizações sem fins lucrativos, incluindo as fundações privadas, voltados para a investigação de instrumentos e práticas de governança que demandem custos relativamente reduzidos de implementação, facilitando a adoção por um maior número de entidades do terceiro setor, cujo porte seja menor em termos de estrutura e abrangência.

Vislumbra-se, ainda, outras linhas de pesquisa a que venham contribuir, no contexto brasileiro, com o aperfeiçoamento da governança das organizações sem fins lucrativos, incluindo as fundações privadas, através da análise de viabilidade e efetividade no tocante à implementação de mecanismos de controle e incentivos, aproveitando o aparato legal existente e a oferta de recursos financeiros (públicos e privados) destinados à execução de atividades sociais através das entidades do terceiro setor.

\section{REFERÊNCIAS}

BEUREN, I. M.. Como elaborar trabalhos monográficos em contabilidade. São Paulo: Atlas, 2003.

BRADSHAW, P.; HAYDAY, B.. Non-profit governance models: Problems and Prospects. The Public Sector Innovation Journal, v.12, n.3, 2007.

CHÊNE, M.. Developing a code of conduct for NGOs. Transparency International, 2009.

COLLINS, J. I. M.. Good to great and the social sectors: A Monograph to Accompany Good to Great. Colorado: HarperCollins Publishers, 2005.

COOPER, D. R.; SCHINDLER, P. S.. Métodos de pesquisa em Administração. 7 ed. São Paulo: Bookman, 2008.

CORNFORTH, C. J.. The governance of public and nonprofit organizations: what do boards do? London: Routledge, 2003. 
COSTA, G. S.. A influência da governança corporativa no desempenho econômico em empresas de capital aberto no Brasil. Porto Alegre: Pontifícia Universidade Católica do Rio Grande do Sul, 2008.

CRANDLEMIRE, D.. Nonprofit boards and effective governance. New Hampshire Business Review, v.34, n.25, 2012.

DEVELLIS, R. F.. Scale development: theory and applications. Newbury Park: SAGE Publications, 1991.

DRUCKER, P. F.. O homem que inventou a Administração. Rio de Janeiro: Elsevier, 2006.

FAITHWORKS.. Faithworks Best Practice Guide. London: Oasis Church Waterloo, 2008.

FUNDAÇÃO ESCOLA NACIONAL DE ADMINISTRAÇÃO PÚBLICA. Normas de conduta para a vida pública. Brasília: ENAP, 1997.

FONTES FILHO, J. R.. Governança cooperativa: diretrizes e mecanismos para fortalecimento da governança em cooperativas. Brasília: BCB, 2009.

GIFE - Grupo de Institutos, Fundações e Empresas. Perspectivas para o marco legal do terceiro setor. São Paulo: GIFE, 2009.

GIL, A. C.. Métodos e técnicas de pesquisa social. São Paulo: Atlas, 1999.

GLAESER, E. L.. The Governance of Not-for-profit Firms. National Bureau of Economic Research. Cambridge: NBER, 2002.

GRESSLER, L. A.. Introdução à pesquisa: projetos e relatórios. São Paulo: Loyola, 2003.

GUNDERSON, C.. Best Practices for Not-for-Profit Internal Controls: Enhancing your Internal Control Environment. Clifton Gunderson LLP: Clifton Gunder, 2008.

HILB, M.. A nova governança corporativa: ferramentas bem-sucedidas para conselho de administração. São Paulo: Saint Paul, 2009.

HODGE, M. M.; PICCOLO, R. F.. Nonprofit board effectiveness, private philanthropy, and financial vulnerability. Public Administration Quarterly, v.35, n.4, p.520-550, 2011.

INSTITUTO BRASILEIRO DE GEOGRAFIA E ESTATÍSTICA. As Fundações Privadas e Associações sem Fins Lucrativos no Brasil em 2010. Rio de Janeiro: IBGE, 2010.

INSTITUTO BRASILEIRO DE GOVERNANÇA CORPORATIVA. Código das Melhores Práticas de Governança Corporativa. 4 ed. São Paulo: IBGC, 2010.

JENSEN, M.; MECKLING, W.. Theory of the firm: managerial behavior, agency costs, and ownership structure. Journal of Financial Economics, v.11, p 5-50, 1976.

KANTER, B.; FINE, A.; ZUCKERBERG, A.. Mídias sociais transformadoras: ação e mudança no terceiro setor. São Paulo: Évora, 2011.

LEW S.; WÓJCIK, D.. The Variegated Cultures of Philanthropy: National and Corporate Impacts on Private Foundation Governance. Competition \& Change, v.14, n.3, p.152-175, 2010.

MAHONEN, J.. Governance in foundations: what can we learn from business firm corporate governance? Finlândia: Universidade de Turku, 2009.

MARCONI, M. A.; LAKATOS, E. M.. Técnicas de pesquisa. 2 ed. São Paulo: Atlas, 1990.

MELO, T. F.. Fiscalização das contas das fundações pelo Ministério Público Estadual. Fortaleza: Ministério Público do Estado do Ceará, 2010.

MINDLIN, S. E.. A governança de fundações e institutos empresariais: um estudo exploratório. São Paulo: Universidade de São Paulo, 2009. 
MOYERS, R. L.. The NonProfit Chief Executive's Ten Basic Responsabilities. Washington: BoardSource, 2006.

NATIONAL COUNCIL FOR VOLUNTARY ORGANISATIONS (NCVO). Being Who You Say You Are: a Guide to Governance for Faith-based Organisations. London: NCVO, 2007.

NETEMEYER, R. G.; BEARDEN, W. O.; SHARMA, S.. Scaling procedures: issues and applications. Thousand Oaks: Sage, 2003.

ORGANIZAÇÃO PARA A COOPERAÇÃO E O DESENVOLVIMENTO ECONÔMICO. Os Princípios da OCDE sobre o Governo das Sociedades. Paris: OCDE, 2004.

OTHMAN, R.; ALI, N.; NORMAH, O.; RAHMAN, A. R.. Practical Challenges in Managing Non-Profit Organizations (NPO): Tales from Two Neighbouring Countries. International Bulletin of Business Administration, v.13, p.1451-243, 2012.

PAES, J. E. S.. Fundações, Associações e Entidades de Interesse Social: Aspectos jurídicos, administrativos, contábeis, trabalhistas e tributários. Rio de Janeiro: Forense, 2013.

PATTON, M. Q.. Qualitative evaluation and research methods. Newbury Park: Sage, 1990.

PICCININI, T. A. A.. Manual prático de direito eclesiástico. São Paulo: Saraiva, 2013.

PINTO, W. S.. A racionalidade da práxis administrativas em fundações corporativas. Revista de Administração da Universidade de São Paulo, São Paulo, v.38, n.4, p.330-342, 2003.

RASSART, C.; MILLER, H.. The effetctive not-for-profit board: a value-driving force. Ottawa: Deloitte Centre for Corporate Governance, 2013.

RENZ, D. O.. Nonprofit Governance and the Work of the Board. Kansas City: University of Missouri, 2007.

RODRIGUES, A. L.; MALO, M. C.. Estruturas de governança e empreendedorismo coletivo: o caso dos doutores da alegria. Revista de Administração Contemporânea, Curitiba, v.10, n.3, 2006.

ROESCH, S. M. A.. A dissertação de mestrado em Administração: proposta de uma tipologia. Revista de Administração, São Paulo, v.31, n.1, p.75-83, 1996.

ROSSETTI, J. P.. Governança Corporativa: fundamentos, desenvolvimento e tendências. São Paulo: Atlas, 2011.

SANCHES, G. P. C.. Governança Corporativa em Firmas sem Fins Lucrativos. São Paulo: Fundação Getúlio Vargas, 2005.

SANTOS, N. C.; SUBLABAN, C. S. Y.; NETO, M. S.; GIULIANI, A. C.; SPERS, V. R. E.. Captação de recursos financeiros em organizações sem fins lucrativos: a utilização de indicadores de gestão para os dadores e beneficiários dos projetos sociais. Revista de Gestão USP, São Paulo, v.15, p.75-91, 2008.

SEGRETI, J. B.; PELEIAS, I. R.; RODRIGUEZ, G. M.. Custos da Atividade de Governança Corporativa sob o enfoque da Controladoria Moderna. In: CONGRESSO INTERNACIONAL DE CUSTOS. 4. Anais. Florianópolis, 2005.

SILVA, C. E. G.; AGUIAR, A. C.. Avaliação de atividades no terceiro setor de Belo Horizonte: da racionalidade subjacente às influências institucionais. Organizações e Sociedade. Salvador, v.18, n.56, p. 35-56, 2011.

SILVA, A. B.; GODOI, C. K.; BANDEIRA-DE-MELLO, R.. Pesquisa qualitativa em estudos organizacionais: Paradigmas, Estratégias e Métodos. São Paulo: Saraiva, 2006.

SILVEIRA, A. D. M.. Governança corporativa no Brasil e no mundo: teoria e prática. Rio de Janeiro: Elsevier, 2010. 
SILVERMAN, D.. Interpretação de dados qualitativos: métodos para análise de entrevistas, textos e interações. Porto Alegre: Artmed, 2009.

SOUZA, S. A.; CARVALHO JÚNIOR, C. V. O.; ALBUQUERQUE, K. S. L. S.. Auditoria externa em organizações do terceiro setor: um estudo da percepção de contadores e não contadores. Revista de Gestão, Finanças e Contabilidade, Salvador, v.2, n.2, p.47-60, 2012.

WEBB, J. W.. Behavioural Orientations of Non-Profit Boards as a Factor in Entrepreneurial Performance: Does Governance Matter?. Journal Of Management Studies, v.48, n.4, 2011.

WORTH, M. J.. Nonprofit management: Principles and Practice. Los Angeles: SAGE, 2013.

YETMAN, M. H.; YETMAN, R. J.. The Effects of Governance on the Accuracy of Charitable Expenses Reported by Nonprofit Organizations. Contemporary Accounting Research, v.29, n.3, p.738-767, 2012.

YIN, R. K.. Case stude research: design and methods. Washington: Sage Publications, 1990. 